\title{
Effect of carbides on erosion resistance of 23-8-N steel
}

\author{
ANIRUDDHA A GADHIKAR*, ASHOK SHARMA, D B GOEL ${ }^{\dagger}$ and C P SHARMA \\ Department of Metallurgical and Materials Engineering, Malaviya National Institute of Technology, Jaipur 302 017, India \\ ${ }^{\dagger}$ Former Department of Metallurgical and Materials Engineering, Indian Institute of Technology, Roorkee 247 667, India \\ (Now at BRCM College of Engineering \& Technology, Bahal 127 028, India)
}

MS received 21 June 2012; revised 7 December 2012

\begin{abstract}
Microstructure is one of the most important parameters influencing erosion behaviour of materials. The role of carbides in the matrix is very complicated in controlling the erosion rate of the materials. Conflicting results have been reported in the literature about the effect of carbides on erosion resistance. Carbides are of great importance especially as obstacles against the penetration of erosive particles into the material surface. However, they are susceptible to cracking and causing matrix decohesion which may increase the overall erosion rate. In 238-N nitronic steel, carbides present in the form of bands are observed to accelerate the erosion rate. Coarse carbides cause depletion of carbon in the austenite matrix which adversely affects the strain hardening tendency thus causing deterioration in erosion resistance of the bulk material. The dissolution of carbides in the austenitic matrix after solution annealing is observed to improve the erosion resistance of 23-8-N nitronic steel.
\end{abstract}

Keywords. Nitronic steel; carbides; slurry erosion; erosion testing.

\section{Introduction}

Erosion of material is a serious and complicated problem in many applications. One of the numerous parameters influencing the erosion resistance of material is the microstructure. The role of carbides in the microstructure is very significant in erosion behaviour of material, but has received little attention of the research community. Carbides, with their high hardness, can blunt the cutting edges and tips of particles impinging on the surface and thus obstruct their penetration into the surface. This may help to reduce the loss of material due to erosion and in turn improve the erosion resistance. However, the brittle carbides may get removed in chunks due to cracking and matrix decohesion. This, conversely, increases the loss of material due to erosion. The morphology (i.e. type, shape, size, volume and distribution) of carbides is another important parameter which controls their effect on erosion behaviour. Few studies in this area have come up with different findings (Ninham and Levy 1988; Hong et al 2001; Cuppari et al 2005; Yaer et al 2008; Chauhan et al 2009; Suchánek et al 2009).

In spheroidized plain carbon steels with carbide volume fraction $<25 \%$, the erosion rate was observed to increase with increase in carbide volume fraction (Ninham and Levy 1988). This was attributed to loss of ductility and inhomogeneous plastic flow which ultimately resulted in fracture and void formation at carbides. On the contrary, fine carbides in a matrix of austenite and martensite were found to impart considerable amount of erosion resistance to high

*Author for correspondence (gadhikar@gmail.com) chromium irons (Seetharamu et al 1995). The erosion resistance of quenched carbon- and low-alloy steels was found to increase with increase in C content (Suchánek et al 2009). It was attributed to the presence of $\mathrm{M}_{7} \mathrm{C}_{3}$ and $\mathrm{M}_{23} \mathrm{C}_{6}$ complex carbides in the microstructure. However, vanadium carbide in ledeburetic $\mathrm{Cr}-\mathrm{V}$ steels and high speed steels did not show any improvement in their erosion resistance in spite of high hardness. The study of effect of hard second phase on cavitation erosion of $\mathrm{Fe}-\mathrm{Cr}-\mathrm{Ni}-\mathrm{C}$ alloys showed that the mass loss in alloys with 25 and $35 \%$ Cr was roughly inversely proportional to the volume fraction of carbides (Cuppari et al 2005). This was attributed to the coarser morphology of $\mathrm{M}_{7} \mathrm{C}_{3}$ carbides present in the microstructure of $25 \% \mathrm{Cr}$ steel.

In a study, the structure with spheroidal carbides in a more continuous ductile ferrite matrix eroded less in comparison to pearlite structure with carbides present as platelets, finely separating the areas of ductile ferrite (Levy 1981). As the distance between brittle carbide spheroids increased, the erosion rate decreased but reverted to increased rate again when particle spacing was too great, owing to low strength ferrite matrix. In another study, it was reported that acute triangular carbides, precipitating at random boundaries, were more likely to lead to cavity nucleation than the plate-like carbides precipitating at coincidence site lattice (CSL) (Hong et al 2001). When the carbide morphology was changed from triangular to planar shape by grain boundary serration with modifying heat treatment, the resistance to cavitation was found to be improved (Kim et al 2004). A study on the erosion behaviour of two kinds of spheroidal carbides cast iron and two types of high chromium cast irons showed that cast irons with spheroidal carbides had superior erosion wear resistance as compared to high chromium cast irons 
(Yaer et al 2008). This was attributed to the dispersion of stress concentration caused by the impact of eroding particles due to spheroidization of carbides in matrix structure through $\mathrm{V}$ addition. A high dispersity of carbides is favourable because large carbides during the impact of erodent particles can be destroyed and can fall out easily.

Some fundamental observations were reported in a study on the influence of primary carbides and test parameters on abrasive and erosive wear of selected high speed steels produced by powder metallurgy technology (Bergman et al 1997). The hardness and ductility of the matrix were observed to control the wear rate when abrasives were significantly harder than primary carbides of high speed steels and there was only small variation with volume fraction, size and type of primary carbides. On the contrary, significant effect was observed on the abrasive and erosive wear resistance with the increased volume fraction of primary carbides when the erosive particles were softer than primary carbides. Chatterjee and Pal (2006) studied the influence of deposit microstructure on erosion behaviour of hard facing alloys deposited on cast iron under different weld procedural conditions. They reported that types of carbides and matrix structure were mainly controlling the erosion rate of deposits when hard quartz sand particles were used as erodent. However, when soft iron-ore particles were used as erodent, the erosion rate decreased with increasing volume fraction of carbides.

Recently, the erosion resistance of cast 21-4-N steel containing hard carbides in continuous and nitrogen strengthened austenitic matrix has been reported to be better than that of 13/4 martensitic steel (Chauhan et al 2008). However, it is further reported that the performance of hot-rolled 21-4-N steel is even better than that of as-cast steel which is attributed to the presence of lesser amount of carbides and their even distribution (Chauhan et al 2009). In other words, the erosion resistance of 21-4-N nitronic steel has been observed to increase with the decrease in carbide contents.

As discussed, contradictory results have been reported on the effect of carbides in different steels on their erosion resistance. Therefore, the picture is still not clear for the effect of presence of carbides on the erosion behaviour of steel. Hence, extensive research is needed in this area. The presence of carbides in given limit may enhance the erosion resistance of the steel (Miller 1992). However, in many applications the presence of carbides is either totally avoided or allowed in suitable proportion with acceptable morphology. This paper presents a critical study on the effect of carbides on the erosion behaviour of $23-8-\mathrm{N}$ nitronic steel.

\section{Experimental}

The experimental procedure of this study includes heat treatment, optical and scanning electron microscopy and mechanical testing of the as-received and heat-treated 23-8-N nitronic steel.

\subsection{Material}

23-8-N nitronic steel is basically austenitic stainless steel containing mainly $\mathrm{Cr}, \mathrm{Ni}, \mathrm{C}$ and $\mathrm{N}$. The composition of the same is given in table 1. Long bars of hot-rolled 23-8-N steel in $100 \times 100 \mathrm{~mm}$ cross section were received from M/S Star Wire (India) Ltd. Ballabgarh, (Haryana) India. The steel specimens were cut from these bars in standard sizes are required for various tests.

\subsection{Heat treatment}

Solution annealing is the most frequently specified heat treatment in order to dissolve the phases, especially carbides that have precipitated during the earlier thermo-mechanical processes. To ensure maximum dissolution of carbides, these steels are solutionized in the temperature range of 980$1175^{\circ} \mathrm{C}$ depending upon the composition. The optimum heat treatment parameters were selected after a systematic study by the authors reported in (Gadhikar et al 2011). Accordingly, in the present investigation, the steel specimens of 20 $\times 20 \times 20 \mathrm{~mm}$ size were subjected to solution heat treatment at $1050^{\circ} \mathrm{C}$ with a holding time of $2 \mathrm{~h}$ followed by water quenching to room temperature.

\subsection{Metallographic examination}

The specimens were ground and polished as per standard metallographic practice for microstructural examination. The samples were etched with aquaregia and then subjected to optical metallography.

\subsection{Mechanical testing}

The standard specimens of 23-8-N steel were prepared for tensile test (as per ASTM E8M-08) and Charpy impact test (as per ASTM E23-07) and were tested at room temperature. Hardness measurements were carried out on the Vickers hardness testing machine by applying $30 \mathrm{~kg}$ load for $10 \mathrm{~s}$.

\subsection{Erosion testing}

Flat specimens having dimensions of $21 \times 55 \times 3 \mathrm{~mm}^{3}$ were tested in a slurry pot erosion tester for total duration of $24 \mathrm{~h}$. The details of the erosion test parameters are given in table 2 . The weight of the specimens was measured after every $2 \mathrm{~h}$ in electronic balance having least count of $0.01 \mathrm{mg}$.

Table 1. Composition of 23-8-N steels (wt $\%$ ).

\begin{tabular}{ccccccccc}
\hline Steel & $\mathrm{C}$ & $\mathrm{N}$ & $\mathrm{Cr}$ & $\mathrm{Ni}$ & $\mathrm{Mn}$ & $\mathrm{Si}$ & $\mathrm{Mo}$ & $\mathrm{Fe}$ \\
\hline $23-8-\mathrm{N}$ & 0.31 & 0.285 & 22.48 & 7.45 & 2.05 & 0.765 & 0.12 & Bal. \\
\hline
\end{tabular}


Table 2. Parameters for erosion testing of nitronic steels.

\begin{tabular}{lc}
\hline Specimen size & $20 \times 55 \times 3 \mathrm{~mm}^{3}$ \\
Average sand particle size & $525 \mu \mathrm{m}$ \\
Stirrer speed & $1000 \mathrm{rpm}$ \\
Specimen rotation speed & $120 \mathrm{rpm}$ \\
Overall sand concentration & $15 \%$ \\
Specific gravity of sand & 2.55 \\
\hline
\end{tabular}

\section{Results}

\subsection{Microstructure}

The microstructures of as-received and heat-treated 23-8-N steel are given in figure 1. It contains carbides (dark phase) in the matrix of austenite (light phase) in as-received condition. The microstructure of $23-8-\mathrm{N}$ steel is heterogeneous in terms of phase distribution and grain size. This may be due to the post-solidification process given to cast ingot in which the cast ingots were hot rolled into a bar of $100 \mathrm{~mm}$ square cross-section. After solution annealing treatment, the bands of carbides have reduced in size to a great extent as compared to those observed in as-received condition. However, the microstructures still reveal the presence of small amount of carbides even after solution annealing at $1050^{\circ} \mathrm{C}$ for $2 \mathrm{~h}$.

\subsection{Mechanical properties}

The comparison of important mechanical properties of 23$8-\mathrm{N}$ steel in as-received as well as heat-treated condition is given in table 3 . The hardness, yield strength and ultimate tensile strength of $23-8-\mathrm{N}$ steel is considerably high in as-received condition presumably due to the presence of greater amount of carbides in as-received condition than heat-treated condition. However, the ductility and impact strength have improved after solution annealing obviously due to the dissolution of carbides.

\subsection{Erosion rate}

The cumulative weight loss of 23-8-N steel observed at the end of the erosion test for $24 \mathrm{~h}$ in as-received and heattreated conditions are shown in figure 2 . It is seen the cumulative weight loss of 23-8-N steel has decreased after solution annealing.

\subsection{Scanning electron metallography of fracture surface}

Figure 3 shows scanning electron micrographs of eroded surface of 23-8-N steel in as-received and heat-treated conditions. The topography of eroded surfaces of as-received 238-N steel reveals deep ploughs and large cavities (figure $3 \mathrm{a}$ ). However, the surface topography of heat-treated 23-8-N eroded steel shows the cutting marks and removal of material in the form of small pockets all over the surface (figure $3 b$ ). Thus, SEM images of eroded surface of 23-8-N steel indicate

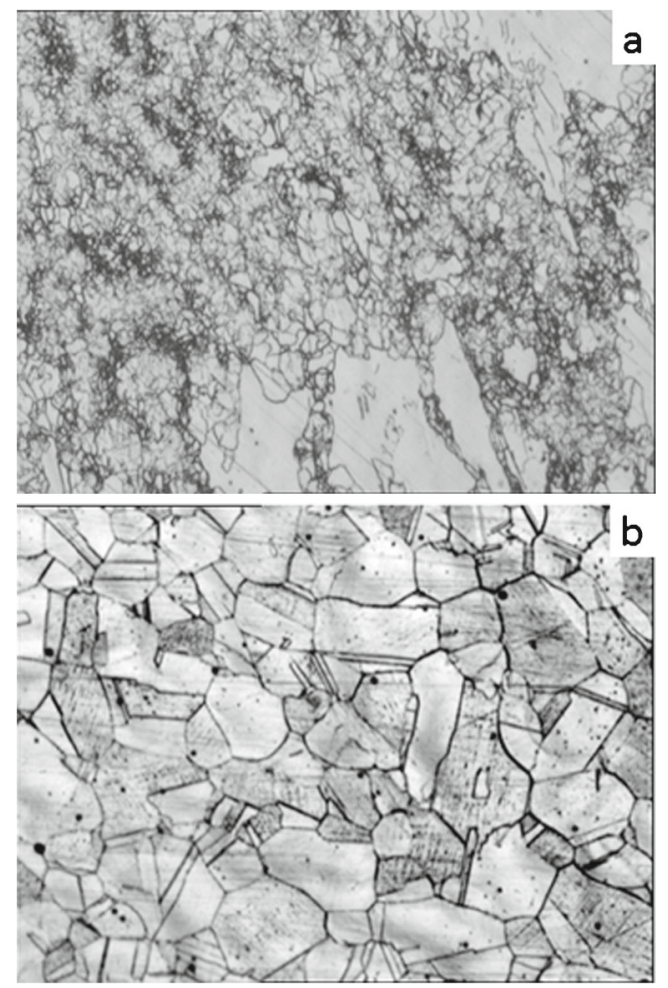

Figure 1. Microstructures of 23-8-N steel in (a) as-received condition and (b) heat-treated condition (solution annealed at $1050{ }^{\circ} \mathrm{C}$ for $120 \mathrm{~min})(100 \times)$.

Table 3. Mechanical properties of as-received (AR) and heattreated (HT) 23-8-N steel.

\begin{tabular}{lcc}
\hline Properties of steel & 23-8-N AR & 23-8-N HT \\
\hline Hardness (VHN) & 280 & 249 \\
YS (MPa) & & \\
$\quad$ (Proof stress @ 0.2\%) & 588 & $433 \cdot 4$ \\
UTS (MPa) & 819 & 823 \\
Ductility (\% elongation) & $27 \cdot 11$ & 59 \\
Impact strength (J) & 85.33 & 155 \\
\hline
\end{tabular}

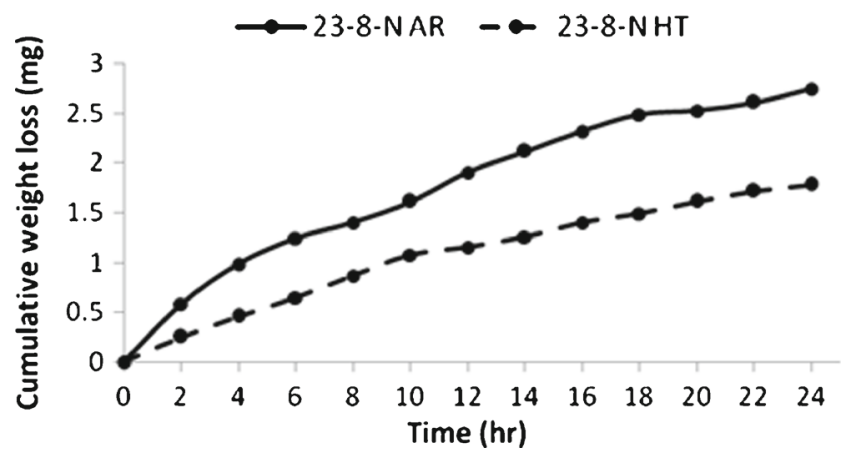

Figure 2. Cumulative weight loss of as-received and heat-treated 23-8-N steel as function of time. 


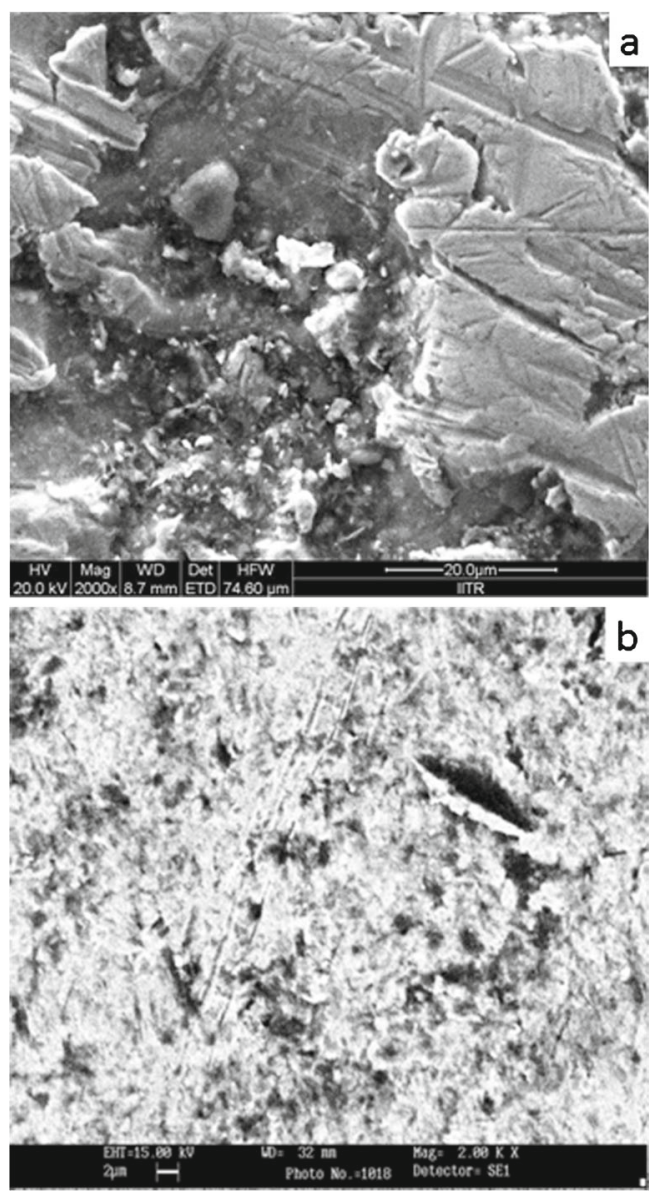

Figure 3. Scanning electron micrographs of eroded surface of 23-8-N steel in (a) as-received condition and (b) heat-treated condition (solution annealed at $1050{ }^{\circ} \mathrm{C}$ for $120 \mathrm{~min}$ ).

the role of cutting as well as deformation wear mechanism in the removal of material. The plough marks are due to the cutting of softer austenitic matrix and the surface cavities are due to the removal of chunks of material as a result of brittle failure of carbide particles and formation of work hardened layers. The formation of lip-like structure is also observed on the eroded surface.

\section{Discussions}

\subsection{Effect of heat treatment on 23-8- $N$ steel}

Table 3 shows enhancement in mechanical properties of 23-8-N steel due to solution heat treatment. As a general trend, the ductility and impact toughness have increased to a great extent with marginal increase in tensile strength. On the contrary, the hardness and yield strength have decreased significantly. All this has happened due to the dissolution of carbides at a high temperature of $1050^{\circ} \mathrm{C}$ with a holding time of $2 \mathrm{~h}$. Water quenching of the specimen after heat treatment has prevented reprecipitation of the carbides. However, fine carbides were still present in the microstructure even after the heat treatment. For further dissolution of carbides, higher temperatures could have been selected, but it would have led to significant coarsening of the austenite grains resulting in inferior mechanical properties. As mechanical properties of the material play important role in the erosion behaviour, the same must be controlled judiciously. Also, it should be noted that complete elimination of carbides would not be possible even at higher temperature (Gadhikar et al 2011) and hence is not practically justifiable to austenitize at higher temperatures. It is wiser to reduce the carbides only to such a level where these will not adversely affect the erosion behaviour significantly.

\subsection{Effect of carbides on erosive weight loss in 23-8-N steel}

23-8-N steel in as-received condition eroded faster than in heat-treated condition. The erosion resistance after heat treatment has improved by approximately $36 \%$. The enhancement in erosion resistance can be attributed to major changes in microstructure and the mechanical properties. The significant change in the microstructure is associated with the dissolution of carbides. In alloy system, the highest erosion resistance has been reported to be obtained either in the solution treated condition or in the over aged condition, where carbides either dissolve or coalesce (Sundararajan 1995). It is now very well established that microstructure has a strong influence on the erosion behaviour of the material. Austenitic microstructure has been preferred for erosion resistant applications owing to its high toughness and plasticity. Major part of the energy exerted by the impinging eroding particles is thus absorbed by the material for plastic deformation. Hence, the material can sustain erosive attack for extended period of time. However, the nitronic steel in present investigation possess a microstructure containing carbides in the softer austenitic matrix. Ideally two phase microstructures, in which harder second phase particles such as carbides are present in ductile metallic matrix, might be expected to exhibit high erosion resistance. However, it is not that simple and straight as it appears. Carbide particles are of complex chemistry and possess high hardness and brittleness. The carbide/matrix interfaces are normally associated with high stress concentration. Therefore, existence of carbides leads to decohesion at the particle/matrix interfaces. Easy formation of cavities and voids leading to fracture thus aggravates the conditions of erosion by the impinging silt particles. The study of the erosion resistance and morphology of spheroidized $\mathrm{Fe}-\mathrm{C}$ alloys suggested that there exist an optimum morphology for the erosion resistance of steels containing carbides (Ninham and Levy 1988). Also, the inter-particle distance between carbides was found to control the erosion resistance (Lindsley and Marder 1998). In the as-received 23-8-N steel under present investigation, the carbides were present in unevenly distributed chunks. SEM images of eroded surface of 23-8-N steel in as-received condition confirm the removal of lumps of carbides. Therefore, the erosive weight loss increased suddenly at the fall of these carbides. This is the reason why the as-received 23-8-N steel showed lot of fluctuations in 
the slope of the erosion curves. Eventually, the cumulative weight loss in as-received condition was much higher in the given test duration. With the dissolution of carbides after the solution annealing treatment, the size of the craters, as revealed in SEM images of the eroded surface of the heattreated 23-8-N steel has reduced remarkably. The small and evenly distributed carbides present in the $23-8-\mathrm{N}$ steel after solution annealing treatment may still be the preferential sites for removal of the material by the impinging erodent particles. However, owing to their small size and number, removal of carbides was not significantly influential in affecting the erosion rate. Hence, the cumulative weight loss of 23-8-N steel in heat-treated condition was significantly lower than that in as-received condition. Also, the erosion curve was smoother without noticeable fluctuations.

\section{Conclusions}

The significant improvement in the mechanical properties of 23-8-N steel occurs after the heat treatment. This is attributed to more effective dissolution of carbides as a result of solution annealing at $1050{ }^{\circ} \mathrm{C}$ for $2 \mathrm{~h}$. The favourable changes in the microstructure and the mechanical properties of 23-8$\mathrm{N}$ steel were subsequently reflected in the significantly better erosion resistance in heat-treated condition. Therefore, in 23-8-N steel all such parameters which produce a good combination of mechanical properties like high ductility and impact strength together with high hardness and simultaneously decrease concentration of carbides lead to high erosion resistance.

\section{Acknowledgement}

We thank M/s Star Wire (India) Ltd., Ballabhgarh (Haryana) India, for the steel supplied for this work.

\section{References}

Bergman F, Hedenqvist P and Hogmark S 1997 Triboiol. Int. 30183

Chatterjee S and Pal T K 2006 Wear 2611069

Chauhan A K, Goel D B and Prakash S 2008 Bull. Mater. Sci. 31 115

Chauhan A K, Goel D B and Prakash S 2009 J. Alloys Compd. 467 459

Cuppari M G D V, Souza R M and Sinatora A 2005 Wear 258596

Gadhikar A A, Sharma C P, Goel D B and Sharma A 2011 Met. Sci. Heat Treat $\mathbf{5 3} 293$

Hong H U, Rho B S and Nam S W 2001 Mater. Sci. Eng. A 318 285

Kim K J, Hong H U, Min K S and Nam S W 2004 Mater. Sci. Eng. A 387-389 531

Levy A V 1981 Wear 68269

Lindsley B A and Marder A R 1998 Metall. Mater. Trans. 29A 1071

Miller J 1992 Metals Handbook, 10th edn, Vol. 18, ASM Int. Materials Park 233

Ninham A J and Levy A V 1988 Wear 121349

Seetharamu S, Sampathkumaran P and Kumar R K 1995 Wear 186-187 159

Suchánek J, Kuklík V and Zdravecká E 2009 Wear 2672092

Sundararajan G 1995 Wear 186-187 129

Yaer X, Shimizu K, Matsumoto H, Kitsudo T and Momono T 2008 Wear 264947 